\title{
Aulas práticas no ensino de botânica: relato de uma experiência no contexto do PIBID em uma escola da rede estadual em Aracaju, SE.
}

Practical classes in the teaching of botany: report of an experience in PIBID context in a state school in Aracaju, SE.

\author{
S. E. C Santana ${ }^{1 *}$; T. S. Silva²; M. F. Landim² \\ ${ }^{1}$ Departamento de Biologia/Laboratório de Ecologia Vegetal, Universidade Federal de Sergipe, 49100-000, São \\ Cristóvão-Sergipe, Brasil
}

*ericaa.bio@hotmail.com

(Recebido em 18 de outubro de 2015; aceito em 29 de outubro de 2016)

\begin{abstract}
A aprendizagem dos conhecimentos biológicos pode contribuir para um efetivo exercício da cidadania, sendo a utilização de recursos didáticos variados, de forma contextualizada, de grande valor para o sucesso desse processo. Este trabalho tem como objetivo analisar e discutir a importância das aulas práticas na abordagem de conteúdos de Botânica no ensino médio, em uma escola da rede estadual de Aracaju, SE, no contexto do PIBID. Foram realizadas duas oficinas, ambas com metodologias didáticas participativas, as quais foram avaliadas quali-quatitativamente. Embora "retraídos", a princípio, os estudantes apresentaram grande interesse e participação nas atividades propostas, as quais representaram também uma oportunidade de se relacionar os conteúdos científicos com a vida diária dos alunos, revelando a necessidade de implantação de estratégias práticas no processo de ensino-aprendizagem.

Palavras-chave: Ensino de Botânica, Aulas práticas, PIBID.
\end{abstract}

The learning of the biological knowledge can contribute to an effective development of citizenship, being the use of various didactical resources, in a contextualized way, of great importance to the success of this process. This work aims to analyze and discuss on the importance of practical classes in approaching Botany contents in a public high school in Aracaju, SE, within the context of the PIBID. Two workshops were planned, both using active didactical methodologies, evaluated qualitative and quantitatively. Though somewhat "introverted", at principle, students presented great interest and participation in the proposed activities, which also represented an opportunity of relating scientific subjects to the student's daily life, emphasizing the importance of practical strategies in the teaching-learning process.

Keywords: Botany classes, practical activities, PIBID.

\section{INTRODUÇÃO}

A educação consiste em um triplo processo, que engloba a humanização, a socialização e a singularização. Dessa forma, ao mesmo tempo em que a educação permite ao indivíduo o ingresso em uma cultura, aquela de um determinado grupo social e que se desenvolve em um dado momento histórico, a apropriação das significações sociais tem, também, um sentido pessoal e único [1].

Nesse sentido, a educação escolar representa mais um ambiente que tem como finalidade auxiliar no processo de formação cidadã dos indivíduos que nela estão inseridos. O ensino de Biologia, especificamente, colabora para a compreensão e aprofundamento de processos e de conceitos biológicos atualizados, oferecendo espaço para as discussões acerca das contribuições e implicações da Ciência e da Tecnologia, contribuindo, assim, para que o cidadão seja capaz de utilizar os conhecimentos escolares em sua vida cotidiana, tomando decisões fundamentadas de interesse individual e coletivo [2].

No ensino médio, a aprendizagem dos conhecimentos biológicos pode proporcionar aos alunos, mais maduros nessa etapa, o desenvolvimento do pensamento crítico para a compreensão 
e discussão de assuntos polêmicos que envolvem a Ciência, considerando a percepção de suas limitações e o discernimento de que ela não tem respostas definitivas para todas as questões, e ainda que possa fornecer subsídios para que o estudante seja capaz de se posicionar e defender seu ponto de vista [3].

Contudo, o excesso de aulas meramente expositivas, ainda predominantemente presentes nas escolas, é um obstáculo para o desenvolvimento de tais competências e habilidades [4]. Essas aulas consistem na transmissão massiva de conteúdos pelo professor, que ocupa o lugar de detentor do conhecimento, cabendo aos estudantes à posição de meros receptores dessas informações, muitas vezes apresentadas de forma descontextualizada. De modo a evitar este currículo enciclopédico e reducionista, centrado na memorização em curto prazo de conceitos e processos, cabe ao docente analisar as potencialidades e limitações dos recursos didáticos disponíveis e sua forma de utilização, bem como selecionar formas avaliativas que proporcionem de maneira efetiva o aprimoramento do educando como pessoa humana [5].

Nesse contexto, destaca-se a importância da utilização da pluralidade metodológica, pois essa se mostra mais eficaz na aprendizagem dos conteúdos, considerando a heterogeneidade inerente a qualquer sala de aula, com diferentes ritmos de aprendizagem dos alunos e experiências vividas pelo grupo social a que pertencem nível de motivação e interesse por uma determinada disciplina e/ou assunto, dentre outros aspectos [6].

A pluralidade metodológica costuma ser particularmente eficaz na abordagem dos conteúdos relacionados à Botânica, os quais usualmente têm pouca aceitação entre os estudantes de diferentes idades e nível de ensino. Infelizmente, muitas das vezes essa rejeição também é apresentada pelos docentes, que optam por abordar esses assuntos no final do ano letivo, de forma superficial e com ênfase apenas na memorização de termos [7]. Esse comportamento é de certa forma, incoerente, pois o estudo das plantas coincide com a história da humanidade, desde os primeiros caçador-coletores, que buscaram nas plantas seu alimento e pouco depois também passaram a utilizá-las no tratamento de doenças, na elaboração de vestimentas e ferramentas [8]. Além disso, as pesquisas científicas na área de Botânica têm apresentado um aumento significativo, devido ao grande interesse das indústrias nas propriedades químicas das plantas, utilizadas na fabricação de fármacos e cosméticos, somada à preocupação com a preservação e restauração das áreas naturais.

Portanto, essa falta de interesse pelos conteúdos botânicos nas aulas de Ciências e Biologia está provavelmente atrelada à abordagem exclusivamente teórica desses assuntos, muitas vezes distante do cotidiano dos estudantes, reforçando a memorização de um grande volume de informações em curto prazo como estratégia didática, estando frequentemente ausentes exemplos da realidade dos alunos, como notícias atualizadas veiculadas na mídia [9].

Os problemas oriundos dessa descontextualização e fragmentação dos conteúdos são visíveis, por exemplo, na dificuldade dos professores em tratarem certas questões ambientais, sociais e mesmo com as de ordem pessoal, o que, consequentemente, dificulta a eficácia dos trabalhos voltados para a sensibilização dos estudantes em relação à qualidade das interações entre os indivíduos e o meio ambiente [10]. Além disso, é importante a abordagem dos conteúdos relacionados à diversidade vegetal enfocando aspectos evolutivos, pois a Biologia evolutiva é considerada um tema central dentro das Ciências Biológicas, uma vez que a sua compreensão é de suma importância para o entendimento de outros conhecimentos da Biologia geral [11].

Dentre o amplo leque de recursos didáticos que podem auxiliar no processo de ensinoaprendizagem dos conteúdos relacionados à Botânica, destacam-se os livros didáticos, amplamente utilizados. No entanto, se por um lado eles representam um valioso auxílio ao professor, podem também, por outro, significar uma limitação à contextualização dos conteúdos abordados. Várias concepções e exemplos contidos em livros de Biologia estão dissociados da realidade da região em que são utilizados [12]. Assim, os professores devem ser capazes de adequar e acrescentar as informações contidas nos livros a partir das realidades e potencialidades locais e globais [13].

Outros recursos didáticos, como as atividades práticas, são usualmente menos utilizados, embora não menos importantes. Estas incluem, mas não se resumem, ao trabalho em laboratório, contribuindo para o desenvolvimento psicomotor, cognitivo e afetivo dos estudantes. Dentre estas, inserem-se a observação e manipulação de espécimes e os jogos, os quais ativam e 
desenvolvem as estruturas cognitivas do cérebro, facilitando o desenvolvimento de novas habilidades, como as de observar, identificar, comparar, classificar, conceituar e relacionar [14]. Para este autor, o Trabalho Laboratorial (TL) inclui atividades que requerem a utilização de materiais de laboratório, mais ou menos convencionais, e que podem ser realizadas num laboratório ou mesmo numa sala de aula normal, desde que não sejam necessárias condições especiais, nomeadamente de segurança, para a realização das atividades.

No entanto, embora monótonas e menos participativas, os professores usualmente restringemse às aulas expositivas por serem de fácil aplicação e não exigirem muito tempo para a sua preparação [15]. As aulas práticas, ao contrário, requerem um maior investimento de tempo e disponibilidade de materiais. São, portanto, de grande importância investimentos na formação (inicial e continuada) de professores que busquem contribuir para a efetivação de aulas mais participativas e contextualizadas. Nesse sentido, destacam-se ações como o Programa Institucional de Bolsa de Iniciação à Docência (PIBID), criado pelo o Decreto $n^{\circ}$ 7.219/2010, que tem a finalidade de fomentar a iniciação a docência, visando à qualificação dos professores e melhoria da educação básica [16].

Sendo assim, o presente trabalho tem como objetivo analisar e discutir uma experiência, no contexto do PIBID, de utilização de aulas práticas na abordagem de conteúdos de Botânica no ensino médio, em uma escola da rede estadual de Aracaju, SE.

\section{MATERIAL E MÉTODOS}

Esta pesquisa é parte das ações do PIBID da Universidade Federal de Sergipe (UFS), realizadas por um projeto do Departamento de Biologia do Campus de São Cristóvão, no ano de 2014, caracterizando-se como pesquisa participante e adotando uma abordagem qualiquantitativa. A pesquisa participante busca fazer com que todos os sujeitos envolvidos, participem ativamente da pesquisa, produzindo conhecimento e intervindo na sua própria realidade [17].

O grupo de pesquisadores é composto por seis bolsistas (licenciandas em Ciências Biológicas pela UFS), um supervisor (professor de Biologia das quatro turmas) e uma coordenadora de área (docente do Departamento de Biologia).

Nesse contexto, retomaram-se as ideias de Laburú, Arruda e Nardi (2003) [18], compreendendo que o processo de ensino aprendizagem é complexo e que a utilização de um único método de ensino torna-se ineficaz, pois alunos retraídos podem ter melhor desempenho em atividades individuais, reflexivas, enquanto outros podem preferir atividades mais dinâmicas, coletivas. Dessa forma, a utilização de uma maior diversidade de metodologias aumenta a possibilidade de atender as diferentes demandas de uma sala de aula naturalmente heterogênea. Baseando-se nessa ideia, no desenvolvimento dessa pesquisa optou-se por trabalhar com metodologias diferentes, na abordagem de um mesmo conteúdo.

O campo empiricamente determinado para este estudo foram quatro turmas de $2^{\circ}$ série do Ensino Médio de uma escola localizada na zona norte de Aracaju, SE. Foram atendidos pelo projeto cerca de 80 estudantes de ambos os gêneros, com idade média de 17 anos.

A pesquisa ocorreu em dois momentos, envolvendo a realização de duas atividades, conduzidas pelas bolsistas e que abordaram o conteúdo referente a Briófitas e Pteridófitas. As ações ocorreram no horário referente a uma das três aulas semanais de Biologia (com a duração de 50 minutos, cada aula) em cada turma, em semanas subsequentes.

A primeira oficina objetivava recapitular o conteúdo ministrado pelo professor da turma e apresentar aos alunos alguns exemplares dos grupos estudados. Esta atividade ocorreu no Laboratório de Informática da escola, já que o Laboratório de Ciências não estava disponível nessa ocasião.

Para a execução da primeira etapa da aula, houve a construção coletiva de um esquema didático no quadro branco, utilizando "fichas de respostas" previamente confeccionadas com as palavras que seriam utilizadas pelos alunos no processo de montagem do esquema. Inicialmente, a bolsista responsável pela atividade escreveu no quadro algumas frases sobre as características referentes ao Reino Plantae e seus quatro grupos - Briófitas, Petridófitas, Gimnospermas e 
Angiospermas, com ênfase nos dois primeiros. Com as fichas dispostas sobre a mesa do professor, os alunos foram convidados a responder às perguntas oralmente e a colar a ficha correspondente a cada pergunta nos lugares apropriados.

O segundo momento desta aula foi destinado à observação e manipulação de exemplares in vivo de Briófitas (musgos) e Pteridófitas (samambaias). Para orientá-los no desenvolvimento da atividade, os alunos receberam um roteiro, no qual deveriam representar, através de desenhos, os organismos por eles observados, realizando a identificação das principais estruturas, além de preencher uma tabela comparativa entre esses dois grupos de plantas, com base nos seus conhecimentos. A última atividade do roteiro consistia de um jogo de "Palavras Cruzadas", que buscava incluir um aspecto lúdico à abordagem do conteúdo. Para a sua resolução, os estudantes se organizaram em pequenos grupos e puderam utilizar fontes de pesquisas diversas, como o livro didático ou mesmo a internet.

Na semana seguinte, a segunda oficina aconteceu na Sala de Vídeo do colégio, por esta dispor de recursos para projeção de uma apresentação em Power Point, elaborada pelas bolsistas, contendo as mesmas questões presentes no roteiro de aula laboratorial solucionado pelos estudantes na oficina anterior. A atividade consistiu na correção, de forma participativa, das questões incluindo as "Palavras Cruzadas", com o objetivo de esclarecer eventuais dúvidas e, assim, auxiliar na aprendizagem dos conteúdos abordados.

Para a avaliação da efetividade das ações propostas, além das observações das bolsistas, foram consideradas as respostas dos alunos em relação à qualidade e adequação dessas oficinas em um questionário misto (questões objetivas e subjetivas), aplicado ao término das atividades do projeto, no ano de 2014.

\section{RESULTADOS E DISCUSSÃO}

A participação dos alunos na construção coletiva do esquema didático, no início da primeira oficina, não foi tão ativa como esperado. Esta atividade teve o intuito de identificar o conhecimento prévio dos estudantes e facilitar a condução da atividade, de acordo com a dinâmica e o nível da turma. A opção pelo uso de "fichas de respostas" previamente confeccionadas para a construção coletiva do esquema ocorreu devido à falta de experiência dos alunos com este tipo de estratégia de ensino-aprendizagem.

Nesse sentido, considerou-se que o estudante não é uma tábula rasa e que traz consigo conhecimentos adquiridos ao longo da vida e também acumulados no decorrer das etapas escolares, logo, toda aprendizagem vem interferir com um "já-existente" conceitual, ainda que, por vezes, falso num plano científico [19].

A princípio, a pouca participação dos estudantes, provavelmente, deve-se ao fato de, ao menos em algumas das turmas, o conteúdo revisado na oficina não ter sido anteriormente abordado com o professor da turma, apesar do planejamento. Outro motivo pode ter sido a timidez de alguns discentes, principalmente no momento de levantar e colar a ficha no quadro, o que deve estar em parte também relacionado ao fato de que as aulas de Biologia nestas turmas, observadas antes do início das atividades do PIBID, foram basicamente expositivas, o que implica em certo "condicionamento" dos alunos em adotar uma atitude passiva, o que pode ter restringido uma participação mais ativa nas atividades propostas pelas bolsistas.

No entanto, isso não significa que mudanças na prática pedagógica não sejam bem-vindas, possíveis ou necessárias, mas que a transição de uma prática tradicional, passiva, para uma mais participativa requer um tempo maior para que os alunos se sintam mais "à vontade" nesta. Isso foi observado, por exemplo, no segundo momento da aula, que contou com uma maior participação dos estudantes, talvez devido à possibilidade de manipulação e observação dos espécimes, tendo despertado a curiosidade deles em relação às características das plantas apresentadas.

A observação é "uma condição e uma atitude de conhecimento que dirige nosso modo de ver e, principalmente, nosso relacionamento com tudo o que nos envolve" [20]. Ao estimular a capacidade de observação dos alunos, a atividade buscou ir além de uma análise superficial dos objetos de estudo, proporcionando, ainda, uma maior aproximação dos estudantes com o conteúdo estudado, combatendo a barreira da abstração. As aulas práticas laboratoriais são, 
portanto, particularmente importantes no ensino de Biologia, permitindo aos alunos a possibilidade de criar e comprovar hipóteses a partir da observação e da análise de fenômenos. No entanto, para que isso ocorra, é necessário que os professores tenham objetivos claramente traçados e um bom planejamento [21].

Apesar da importância das aulas práticas laboratoriais, foram encontradas dificuldades para a utilização do Laboratório de Ciências da escola, há muito tempo desativado, com vidrarias quebradas e soluções químicas cuja validade já havia sido expirada, além da urgente necessidade de limpeza, de forma geral. A utilização desse espaço poderia contribuir para a realização de atividades mais dinâmicas e que contribuíssem para a mobilização do estudante, despertando nele o desejo de aprender [22]. Contudo, é necessário ressaltar que, paralelamente à capacitação do professor, são também necessários investimentos na infraestrutura física e em recursos humanos para que espaços como o Laboratório de Ciências, Sala de Informática e outros sejam efetivamente utilizados.

$\mathrm{Na}$ atividade que envolvia a manipulação e observação de espécimes, observou-se que os exemplares de musgos foram, a princípio, confundidos pelos alunos com gramíneas e grupos de algas conhecidas popularmente como "limo", percebendo-se certa confusão em relação à classificação biológica desses seres vivos. De fato, os estudantes apresentam frequentemente muitas dúvidas em relação à classificação biológica e costumeiramente fazem associações similares ao que os primeiros estudiosos faziam, a exemplo de Aristóteles, que classificava todos os organismos vivos como "plantas" ou "animais" [23].

No que se refere à classificação dos organismos pertencentes ao Reino Plantae, novas características, que não somente as morfológicas vêm sendo recentemente utilizadas para enquadrá-los em tais categorias, a exemplo da recente classificação filogenética das Angiospermas (APG III), baseada em grande parte em caracteres moleculares [24]. Sendo assim, há uma constante necessidade do conteúdo apresentado no ensino básico acompanhar o progresso científico atual, de modo contextualizado, através da utilização dos meios de comunicação, que permitem que as informações científicas extrapolem os muros das universidades e instituições de pesquisas e tornem-se acessíveis à população em geral [25]

É interessante ressaltar que, no decorrer da atividade, percebeu-se que os exemplares de musgos e samambaias levados para a aula eram de espécies já conhecidas pelos estudantes. No entanto, estes ainda não tinham notado a sua relação com os conteúdos estudados em sala de aula e nem haviam sidos sensibilizados a analisarem suas estruturas, identificando, inclusive, sua importância ecológica. Este resultado revela a importância da contextualização dos conteúdos apresentados em sala de aula, associando-os à realidade dos alunos.

Nessa oportunidade, também se chamou a atenção para as diferenças entre as imagens esquemáticas apresentadas nos livros didáticos e a morfologia do musgo in vivo. Isso é importante, considerando que a contribuição da maioria dos livros didáticos para o ensino de Ciências e Biologia, especificamente sobre os conteúdos de Botânica, merece alguma reflexão, pois muitas das imagens neles apresentadas se distanciam bastante do tamanho real, sem fornecer nenhuma escala de aumento ou redução [26]. Esse fato impossibilita ou dificulta, muitas vezes, o reconhecimento destes organismos ou de suas estruturas pelos alunos. Por isso, a possibilidade de visualização e manipulação de material referente ao conteúdo estudado em atividades práticas, levando em consideração a realidade local, com suas características próprias, e permitindo a inclusão de novos dados ou informações, além das contidas no livro didático adotado, é extremamente necessária.

Nesta oficina, a visualização dos exemplares foi feita com o auxílio de lupas de mão, com as quais os alunos puderam observar o gametófito e o esporófito, detalhando suas estruturas características e, dessa forma, diferenciando-os. Os estudantes também foram instigados a analisar a relação entre o tamanho dos musgos, seu hábito de vida e sua dependência da água para a reprodução. No caso das samambaias, os discentes conseguiram ainda observar os esporos presentes no soro, sendo estes liberados nas suas próprias mãos, podendo dessa forma entender a importância dessa estrutura para a reprodução das Pteridófitas.

Em relação aos seus aspectos evolutivos, embora as Briófitas e Pteridófitas sejam consideradas grupos basais [27], enfatizou-se para os discentes que isso não quer dizer que existam seres vivos "melhores" que os demais, mas sim diferentemente adaptados às condições 
em que surgiram e evoluíram. Nessa perspectiva, a última questão do roteiro pedia que os alunos completassem uma tabela comparativa entre os dois grupos, momento em que eles podiam perceber as mudanças evolutivas ocorridas no Reino Plantae.

Os Parâmetros Curriculares Nacionais para o Ensino Médio destacam a importância do enfoque evolutivo no Ensino de Botânica, a fim de auxiliar na compreensão da origem e das adaptações de cada grupo/espécie e assim relacionar a evolução com o ambiente e as estruturas presentes [28]. Portanto, o ensino com abordagens de aspectos evolutivos tende a propiciar uma aprendizagem significativa por parte dos alunos, pois eles conseguem ter uma visão do processo gradual que é a evolução e percebem a complexidade conquistada pelos organismos [29].

Por fim, observou-se, durante o desenvolvimento da primeira oficina, que os estudantes apresentavam certa dificuldade em relação à escrita e até mesmo à pronúncia de alguns termos científicos ("esporófito", "gametófito", "pteridófitas", dentre outros). A aquisição do vocabulário científico, dos termos básicos que engloba conceitos referentes à Ciência e a Tecnologia, são de suma importância no processo de alfabetização científico-tecnológica dos estudantes, propiciando meios para que possam ler e interpretar essas informações [30].

Nesse sentido, buscou-se ajudar os alunos a se familiarizarem com os termos científicos abordados nesse conteúdo, de forma lúdica, através da resolução de "Palavras Cruzadas", atividade que os mobilizou na procura de respostas para as questões, tornando-os ativos na sua própria aprendizagem. Inicialmente, a dinâmica foi realizada por duplas ou trios, mas, por falta de tempo, o preenchimento das lacunas restantes foi sugerido como "exercício para casa", uma vez que os estudantes trariam o roteiro solucionado na oficina posterior.

A segunda oficina consistiu na correção das atividades realizadas na semana anterior. A experiência foi muito proveitosa, sendo possível avaliar o nível de aprendizagem dos alunos, que em sua maioria conseguiram lembrar as principais características dos dois grupos estudados e das informações discutidas. Quanto às "Palavras Cruzadas", observou-se que grande parte dos discentes havia finalizado a atividade em casa, talvez em parte pelo fato de ser uma atividade lúdica, e não apresentaram dificuldade na sua resolução.

Nesse aspecto, há uma discrepância entre o "tempo de ensinar" e o "tempo de aprender", sendo o primeiro cronometrado para atender a demanda do currículo, que se preocupa com a quantidade de conteúdos ministrados e menos com a qualidade da aprendizagem, assimilando-se a uma "linha de produção". É de suma importância a retomada de conteúdos já abordados nas aulas, com a realização de "pausas" antes da introdução de novos assuntos, para que realmente haja a apropriação do conhecimento por parte dos estudantes [31].

É interessante notar que estas aulas apresentaram a melhor avaliação por parte dos alunos, dentre as demais desenvolvidas durante o ano de 2014, sendo que a grande maioria deles (41 de um total de 52) afirmou ter gostado das atividades e somente nove deles disseram ter gostado pouco.

A análise das bolsistas em relação a essas ações também foi positiva, pois grande parte dos objetivos traçados no planejamento foram alcançados e as oficinas propiciaram uma participação ativa dos estudantes no processo de aprendizagem, de forma dinâmica e contextualizada. Além disso, considerando-se as nítidas diferenças observadas entre os alunos das quatro turmas, a utilização de metodologias didáticas variadas tornou-se de suma importância na mobilização dos estudantes para a construção do saber.

\section{CONCLUSÃO}

De forma geral, percebeu-se que houve oportunidades de aprendizagem para todos os envolvidos na pesquisa. Para os estudantes da turma onde se desenvolveu o projeto, possibilitou um auxílio no entendimento do conteúdo programático, de forma contextualizada e dinâmica. A utilização de metodologias que mobilizem os alunos a observarem e manipularem materiais in vivo são uma estratégia favorável à aprendizagem no ensino de Biologia, além de representar a 
oportunidade de problematizar questões do âmbito da Ciência que estão presentes no cotidiano dos discentes.

Em relação às contribuições do PIBID na formação docente, pode-se considerar que a experiência é singular, pois propicia uma constante troca entre professores em formação, em serviço e formadores de professores, de modo a estimular a partilha de experiência e o planejamento de ações em prol da melhoria da educação básica. Nesse sentido, a possibilidade de as bolsistas poderem vivenciar a dinâmica escolar e as especificidades de cada turma, podendo refletir sobre a prática docente e elaborar estratégias que melhor facilitem a apropriação do conhecimento pelos estudantes, é essencial para a melhoria de sua formação inicial.

\section{AGRADECIMENTOS}

Agradecemos à Coordenação de Aperfeiçoamento Pessoal de Nível Superior-CAPES pelo financiamento da pesquisa.

\section{REFERÊNCIAS BIBLIOGRÁFICAS}

1. Charlot B. Relação com o saber, Formação dos Professores e Globalização - Questões para a educação hoje. Trad. Sandra Loguercio. Porto Alegre: Artmed, 2005. 159p.

2. Krasilchik M. Prática de Ensino de Biologia. 4 ed. São Paulo: Editora da Universidade de São Paulo, 2004. $198 \mathrm{p}$.

3. Brasil. Ministério da Educação (MEC), Secretária de Educação Média e Tecnológica (Sentec). Parâmetros Curriculares para o Ensino Médio. Brasília 1999.

4. Leão DMM. Paradigmas contemporâneos da educação: a escola tradicional e a escola construtivista. Caderno de Pesquisa 1999. 187-206.

5. Carvalho AMP, Gil-Pérez D. Formação de professores de ciências. 7 ed. São Paulo: Cortez, 2003,117p.

6. Laburú CE, Arruda SM, Nardi R. Pluralismo metodológico no ensino de ciências. Ciência \& Educação. Bauru 2003; 9(2): 247-260.

7. Martins CMC, Braga SAM. As idéias dos estudantes, o ensino de biologia vegetal e o vestibular da UFMG. In: Encontro nacional de pesquisa em educação em ciências; 1999 Set 01-04; Valinhos, São Paulo, p. 1-11.

8. Silva, PGP. O ensino da botânica no nível fundamental: um enfoque nos procedimentos metodológicos, 2008. [Tese] Faculdade de Ciências, Universidade Estadual Paulista, Bauru, 2008.148 p.

9. Kinoshita LS, Torres RB, Tamahiro JY, Forni-Martins ER. A Botânica no Ensino Básico: relatos de uma experiência transformadora. São Carlos-SP, Rima, 2006. 162p.

10. Busato IRH. Desenvolvimento de metodologia adequada à disciplina de Biologia, que permita uma diminuição da visão fragmentada do saber e contemple uma visão mais integrada e holística [Dissertação de Mestrado], Universidade Federal de Santa Catarina, Florianópolis, 2001.

11. Mayr EO, Desenvolvimento do pensamento biológico. 4 ed. Brasília: UnB, 2009. 1107p

12. Sales AB, Landim MF. Análise da abordagem da flora nativa em livros didáticos de biologia usados em escolas de Aracaju-SE. Experiências em Ensino de Ciências (UFRGS), 2009; 4(3): 17-29.

13. Figueiredo JA, Coutinho FA, Amaral FCO. Ensino de botânica em uma abordagem ciência, tecnologia e sociedade. In: II Seminário Hispano Brasileiro - CTS. São Paulo, UNICSUL, 2012. 488-498.

14. Hodson D. Experiments in science teaching. Educational Philosophy and Theory, 1988; 20(2): 53-66.

15. Silva FSS, Morais LJO, Cunha JPR. Dificuldades dos professores de biologia em ministrar aulas práticas em escolas públicas e privadas do município de imperatriz (MA). Revista UNI, Imperatriz-MA, $2011 \mathrm{jan} / \mathrm{jul} ; 1$ (1): 135-149.

16. Capes - Coordenação de Aperfeiçoamento de Pessoal de Nível Superior. Programa Institucional de Bolsa de Iniciação à Docência-PIBID. Disponível em<http://www.capes.gov.br/educacaobasica/capespibid>Acesso em: 17 de junho de 2015.

17. Demo P. Pesquisa participante: mito e realidade. Rio de Janeiro: Senac, 1984.

18. Laburú CE, Arruda SM, Nardi R. Pluralismo metodológico no ensino de ciências. Ciência \& Educação. Bauru 2003; 9(2): 247-260.

19. Astolfi JP, Develay M. A Didática das Ciências. 12 ed. Campinas: Papirus, 2008. 132p.

20. Ferrara LDA. Leitura sem palavras. São Paulo: Ática (Série Princípios), 2001. 72 p.

21. Borges AB. Novos rumos para o laboratório escolar de ciências. Caderno Brasileiro de Ensino de Física, Belo Horizonte-MG 2002; 19(3): 291-313. 
22. Charlot B. Relação com o saber, Formação dos Professores e Globalização - Questões para a educação hoje. Trad. Sandra Loguercio. Porto Alegre: Artmed, 2005. 159p.

23. Apg - Angiosperm Phylogeny Group. An update of the Angiosperm Phylogeny Group classification for the orders and families of flowering plants: APG III. Botanical Journal of the Linnean Society 2009. 105-121.

24. Martins RA, Martins LCP, Uma leitura biológica do De anima de Aristóteles. Filosofia e História da Biologia 2007. 405-426.

25. Pechula MR. A ciência nos meios de comunicação de massa: divulgação de conhecimento ou reforço do imaginário social? Ciência e Educação, Bauru 2007; 13(2): 211-222.

26. Megid N, Fracalazan H. O livro didático de ciências: problemas e soluções. Ciência e Educação 2003; 2(2): 147-157.

27. Raven, P. H.; Evert, R.F.; Eichhorn S. E. Biologia Vegetal. 7 ed, Guanabara Koogan, RJ, 2007.

28. Brasil. Ministério da Educação (MEC), Secretária de Educação Média e Tecnológica (Sentec). Parâmetros Curriculares para o Ensino Médio. Brasília, 1999.

29. Bopp TR. Professor mediador: gerando interesses no aprendizado de Botânica em estudantes do Ensino Médio. 2013. 64p. [Monografia], Instituto de Biociências, Universidade Federal do Rio Grande do Sul, Porto Alegre-RS.

30. Lorenzetti L, Delizoicov D. Alfabetização científica no contexto das séries iniciais, Ensaio - Pesquisa em Educação em Ciências 2001; 3(1): 37-50.

31. Gatti BA, Barretto ESS, André MEDA. Políticas docentes no Brasil: um estado da arte. Brasília: Unesco, 2011. 300 p. 